\title{
MEMAKSIMALKAN DAYA TARIK ALAMIAH SEBAGAI STRATEGI PENGEMBANGAN WISATA ALAM GUNUNG PINANG SERANG BANTEN
}

\section{(Maximizing Natural Attraction as A Strategy for The Development of Natural Tourism in Gunung Pinang Serang Banten)}

\author{
Suliyanti ${ }^{1}$, Ratna Sari Hasibuan ${ }^{2}$, Ken Dara Cita ${ }^{3}$ \\ ${ }^{1}$ Dinas Lingkungan Hidup dan Kehutanan Provinsi Banten, Kawasan Pusat Pemerintahan Provinsi Banten (KP3B) \\ JL. Raya Curug Kota Serang - Banten \\ e-mail : suliyanti02@gmail.com \\ ${ }^{2}$ Progam Studi Kehutanan, Kehutanan, Universitas Nusa Bangsa \\ Jl. KH. Soleh Iskandar KM.4 Kelurahan Cibadak Tanah Sareal, Kota Bogor , 16166 \\ email : ratnasylva@gmail.com \\ ${ }^{3}$ Progam Studi Kehutanan, Kehutanan, Universitas Nusa Bangsa \\ J1. KH. Soleh Iskandar KM.4 Kelurahan Cibadak Tanah Sareal, Kota Bogor , 16166 \\ email: kendarac@gmail.com
}

Corespondent author : $\underline{\text { ratnasylva@gmail.com }}$

\begin{abstract}
Gunung Pinang Nature Tourism is located in Kramatwatu District, Serang Regency. This nature tourism is managed by Perum Perhutani. This tour offers tourist attractions in the form of nature photos with the beauty background of Serang Regency. A variety of photo attractions are offered in this nature tourism. Affordable ticket prices make this natural tourism as one of nature tourism in Serang District. This research was conducted to determine the attraction of tourist attractions in Gunung Pinang natural Tourism, the method of study used is the assessment of ODTWA in the form of scoring or ranking on the potential of Gunung Pinang natural tourism based on guidelines according to Dirjen PHKA 2003 and SWOT analysis. The Data that is examined is the attraction of tourism objects, accessibility, environmental conditions, accommodation, supporting facilities and infrastructure, availability of clean water and safety.Then formulate the internal and external factors of the SWOT matrix as a SWOT analysis. Based on the results of the research of Gunung Pinang nature Tourism has a percentage of ODTWA assessment of $81.63 \%$, so it is worth to be developed, then based on the SWOT analysis that has been done then it is known that the total score of EFI = 1.22 and the total value of EFE $=$ 0.95 score appears that the chosen strategy is in the Quadrant I (one), which is an aggressive strategy. This position that was absolutely strategic ecotourism the further investigated in the the ecotourism program. This is clearly for the purpose of compelling more visitors to Gunung Pinang Natural Tourism.
\end{abstract}

Keywords : Development, Ecotourism, Gunung Pinang Natural Tourism

\begin{abstract}
ABSTRAK
Wisata Alam Gunung Pinang berada di Kecamatan Kramatwatu, Kabupaten Serang. Wisata alam ini dikelola oleh Perum Perhutani. Atraksi wisata yang ditawarkan berupa foto alam dengan background keindahan Kabupaten Serang. Beragam atraksi wisata foto ditawarkan di wisata alam ini. Harga tiket yang terjangkau menjadikan wisata alam ini sebagai salah satu primadona wisata alam di Kabupaten Serang. Penelitian ini dilakukan untuk menentukan penilaian Obyek Daya Tarik Wisata di Wisata Alam Gunung Pinang, metode penelitian yang digunakan adalah penilaian ODTWA berupa pemberian skor atau ranking pada potensi di Wisata Alam Gunung Pinang berdasarkan pedoman menurut Dirjen PHKA 2003 dan Analisis SWOT. Berdasarkan hasil penelitian kawasan Wisata Alam Gunung Pinang memiliki presentase penilaian ODTWA sebesar 81,63\%, sehingga Layak dikembangkan, kemudian berdasarkan analisis SWOT maka diketahui bahwa nilai total skor $\mathbf{E F I}=\mathbf{1 , 2 2}$ dan nilai total skor $\mathbf{E F E}=\mathbf{0 , 9 5}$ tampak bahwa strategi yang dipilih berada pada Kuadran I (satu) $(\mathbf{0 , 9 5 ; 1 , 2 2 )}$ yaitu strategi Agresif. Posisi ini sangat strategis untuk dilakukan pengembangan ekowisata berupa penambahan wahana dan pembuatan program ekowisata untuk menarik minat pengunjung ke Wisata Alam Gunung Pinang.
\end{abstract}

Kata kunci: Pengembangan, Ekowisata, Wisata Alam Gunung Pinang 


\section{PENDAHULUAN}

Beberapa hasil kajian mengenai pengembangan ekowisata seperti Bahiyah (2018), Hasibuan (2019), Suryani (2020) menyatakan bahwa untuk mengembangkan ekowisata harus mengetahui potensi objek wisata yang akan dikembangkan. Hasil kajian menyarankan agar memaksimalkan kekuatan internal yang dimiliki seperti daya tarik dari flora fauna, keindahan alam dan memanfaatkan dan mengembangkan peluang yang ada, seperti mengembangkan atraksi, pembuatan program-program wisata dan pemberdayaan masyarakat, meningkatkan promosi baik dari media cetak maupun media sosial.

Pengembangan ekowisata menjadikan masyarakat sekitar hutan lebih sejahtera di bidang ekonomi. Pemanfaatan sumberdaya lokal yang optimal dalam konteks upaya konservasi, pemberdayaan ekonomi lokal dan kultur budaya mampu memberikan nilai lebih tinggi tidak hanya pada sektor ekonomi pengelola, namun juga terhadap masyarakat secara umum dalam peningkatan ekonomi. Ini berarti pengembangan ekowisata dengan strategi berbasis penggalian potensi keragaman wahana wisata alamiah merupakan informasi dan pengetahuan penting.

Kawasan Wisata Alam Gunung Pinang berada di Kecamatan Kramatwatu, Kabupaten Serang, Provinsi Banten Wisata. Wisata alam ini dikelola oleh Perum Perhutani dengan menawarkan wahana wisata berupa foto dengan latar keindahan alam dan harga tiket relatif murah, sehingga menjadi salah satu primadona wisata alam. Kondisi tersebut memunculkan pertanyaan. Apa daya tarik lokasi wisata ini? Strategi seperti apakah yang sesuai untuk pengembangan ekowisata ini?

Penelitian ini bertujuan untuk menilai obyek dan daya tarik wisata alam yang ada di kawasan Wisata Alam Gunung Pinang. Selain itu, untuk menganalisis permasalahan dan strategi pengembangan wisata alamnya.

\section{METODE PENELITIAN}

Penelitian dilaksanakan pada bulan Maret 2020 sampai dengan bulan Mei 2020, dengan metode penelitian studi kasus. Objek wisata yang dikaji adalah Wisata Alam Gunung Pinang, di Kabupaten Serang, Provinsi Banten (Gambar 1). Data dikumpulkan melalui wawancara dan observasi lapang.

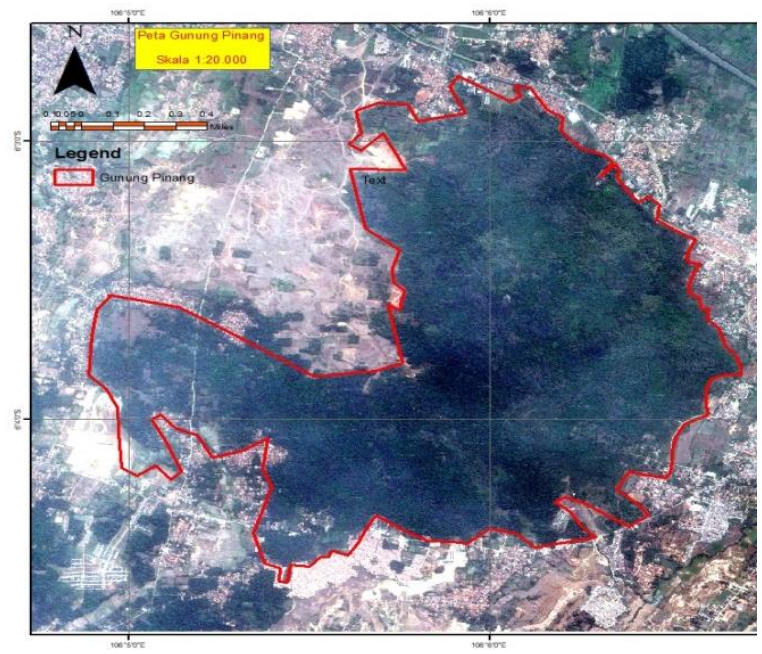

Gambar 1. Peta lokasi Wisata Alam Gunung Pinang

Responden penelitian ditetapkan sebanyak 30 orang (Sugiono, 2009), terdiri dari: masyarakat sekitar Wisata Alam Gunung Pinang 10 orang (tukang parkir 2, pedagang 3, masyarakat setempat 5), pengunjung 17 orang dan pengelola kawasan Wisata Alam Gunung Pinang 2 orang (Perum Perhutani) serta 1 orang dari Dinas Pariwisata Provinsi Banten.

Penilaian obyek dan daya tarik wisata alam di kawasan Wisata Alam Gunung Pinang dilakukan menggunakan pedoman penilaian Objek Daya Tarik Wisata Alam - ODTWA (Dirjen PHKA, 2003; Zen et. al., 2018; Hasibuan dan Cita, 2020). Komponen yang dicatat dan dinilai adalah:

- Bobot 6 dari daya tarik meliputi keindahan alam dan keunikan, banyaknya sumbar daya alam yang menonjol, keutuhan sumberdaya alam, kenyamanan, kebersihan dan jenis kegiatan aktivitas wisata alam. 
- Bobot 5 dari aksesibilitas meliputi jarak dari kota ke lokasi wisata, kondisi jalan, tipe jalan dan waktu tempuh dari kota;

- Bobot 5 dari Kondisi sekitar kawasan yang diperoleh dari tata ruang wilayah obyek, ruang gerak pengunjung, tanggapan masyarakat terhadap pengembangan.

- Bobot 3 diperoleh dari akomodasi seperti jumlah akomodasi dan jumlah kamar.

- Bobot 3 dari sarana dan prasarana meliputi sarana prasarana penunjang yang ada dalam radius $5 \mathrm{~km}$ dari lokasi wisata.

- Bobot 6 dari Ketersediaan air bersih karena Ketersediaan air bersih merupakan faktor penting dalam sebuah pengembangan kawasan wisata.

- Bobot 5 dari Keamanan karena hal ini berhubungan dengan kenyamanan pengunjung dan keamanan yang baik dan terkontrol akan membuat pengunjung untuk meluangkan waktu lama saat melakukan kunjungan wisata.

Jumlah nilai untuk satu kriteria dihitung menggunakan rumus

$$
\mathrm{S}=\mathrm{N} \times \mathrm{B}
$$

Keterangan:

$\mathrm{S}=$ skor/nilai suatu kriteria

$\mathrm{N}=$ jumlah nilai unsur-unsur pada kriteria

$\mathrm{B}=$ bobot nilai

Skor yang diperoleh kemudian dibandingkan dengan skor total tertinggi suatu kriteria agar memperoleh tingkat kelayakan. Indeks kelayakan suatu kawasan ekowisata adalah sebagai berikut (Karsudi 2010):

Nilai Indeks Kelayakan $=\frac{\text { Skor Kriteria }}{\text { Skor Total Kriteria }} \times 100 \%$

Kawasan ekowisata dinyatakan layak jika nilai indeks > 66,6\%, belum layak dikembangkan jika nilai indeks pada kisaran $33,3 \%$ - 66,6\%, serta tidak layak dikembangkan jika nilai indeks $<33,3 \%$.

Strategi pengembangan wisata alam dapat diketahui menggunakan analisis
Strength Weakness Opportunity Treath SWOT (Rangkuti, 2014). Hasil analisis kemudian dibahas secara deskriptif.

\section{HASIL DAN PEMBAHASAN}

\section{Karakteristik Pengunjung}

Pengunjung merupakan seseorang yang lebih dari 24 jam ke tempat yang berbeda di luar tempat domisilinya (Ali, 2015). Berdasarkan hasil penelitian, mayoritas pengunjung berjenis kelamin laki-laki (53\%). Kelas umur pengunjung dibedakan menjadi umur 17-20 tahun (6\%) dan umur 21-53 tahun (94\%). Pengunjung didominasi oleh mereka yang sudah menikah $(65 \%)$.

Pekerjaan pengunjung Kawasan wisata dibagi menjadi enam kategori yang meliputi, pelajar/mahasiswa, TNI/POLRI, wiraswasta/ pengusaha, Pegawai Negeri Sipil (PNS), pegawai swasta dan lainnya. Hasil mayoritas pekerjaan yang dimiliki pengunjung adalah Pegawai Negeri Sipil dengan prosentase sebesar $41 \%$ (Gambar 2).

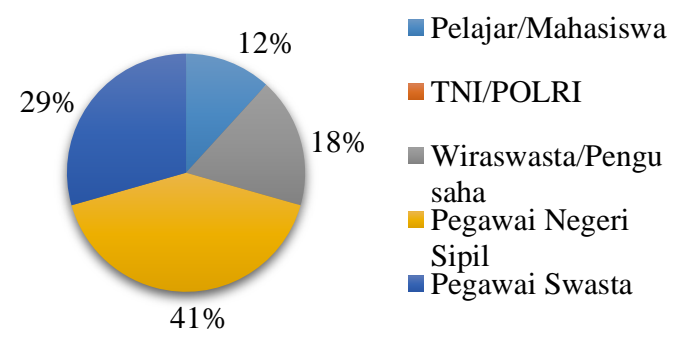

Gambar 2. Pekerjaan Pengunjung

Asal kedatangan pengunjung dikategorikan menjadi empat wilayah yaitu, Kota Serang, Kabupaten Serang, Kota Cilegon dan Kabupaten Lebak. Adapun untuk asal kedatangan pengunjung yang datang mayoritas berasal dari Kota Serang (Gambar 3).

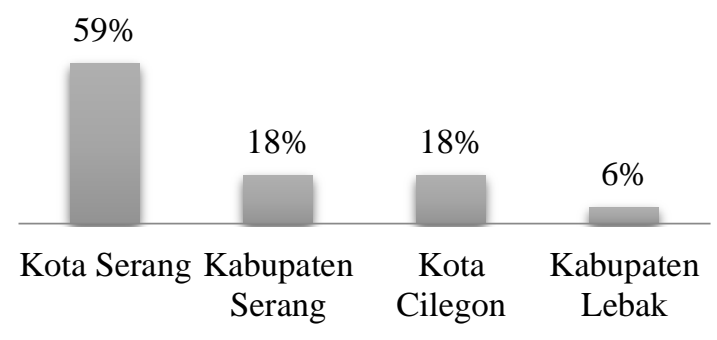

Gambar 3. Asal Kedatangan Pengunjung 


\section{Motivasi Pengunjung}

Menurut Pitana dan Gayatri (2005) motivasi perjalanan seseorang dipengaruhi oleh dua faktor, yaitu faktor internal wisatawan itu sendiri (intrinsic) dan faktor eksternal (extrinsic motivation). Motivasi intrinsik terbentuk dari kebutuhan fisologis, kebutuhan keamanan, kebutuhan sosial, kebutuhan prestise dan kebutuhan aktualisasi diri.

Hasil penelitian mengkategorikan frekuensi kunjungan di Wisata Alam Gunung Pinang dibagi menjadi tiga, yaitu, 1-3 kali, 4-7 kali dan >11-14 kali. Jumlah kunjungan 1-3 kali mendominasi prosentase kunjungan (Gambar 4).

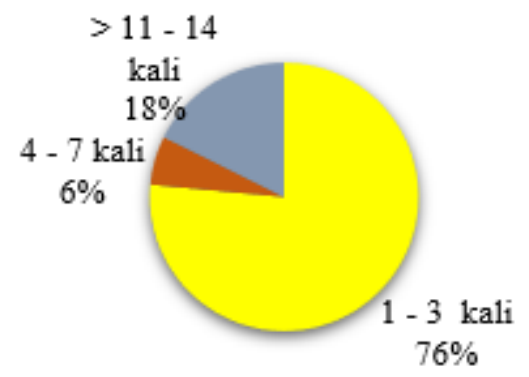

Gambar 4. Frekuensi Kunjungan Pengunjung

Penggunaan transportasi pengunjung terbagi menjadi tiga yaitu, mobil, motor dan jalan kaki. Mayoritas pengunjung menggunakan mobil (Gambar 5).

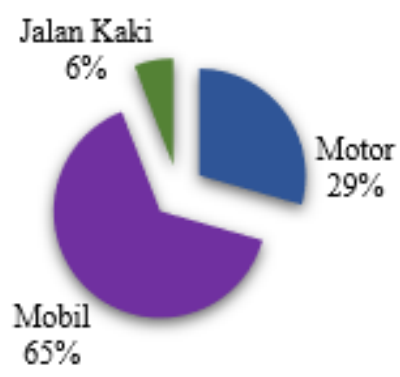

Gambar 5. Transportasi Pengunjung

Pengeluaran biaya oleh pengunjung di terbagi menjadi empat kategori, yaitu <Rp.100.000, Rp.100.000 - Rp.250.000 dan Rp.250.000 - Rp.500.000 serta > Rp.500.000.
Biaya kunjungan sebesar <Rp.100.000 menjadi nilai yang dominan (Gambar 6).

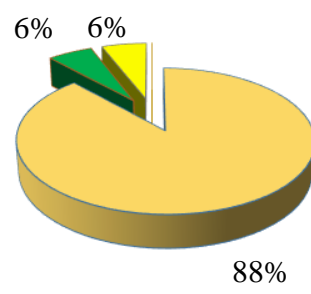

$$
\begin{gathered}
\square<\text { Rp. } 100.000 \\
\square \text { Rp.100.000- } \\
\text { Rp.250.000 } \\
\square \text { Rp.250.000- } \\
\text { Rp.500.000 }
\end{gathered}
$$

Gambar 6. Biaya yang Dikeluarkan Pengunjung

Jarak antara asal pengunjung dengan Wisata Alam Gunung Pinang terbagi menjadi empat yaitu, <10 km, 10-20 km, 21-30 km, dan $>30 \mathrm{~km}$. Jarak destinasi $<10 \mathrm{~km}$ mendapatkan prosentase yang dominan (Gambar 7).

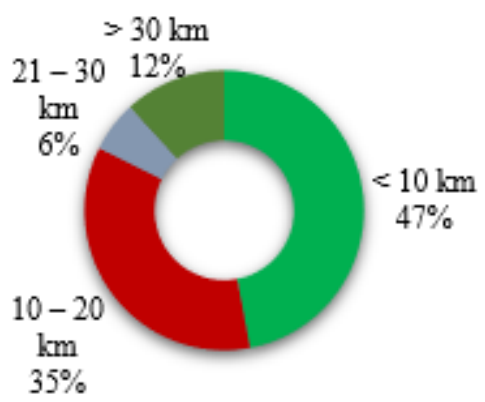

Gambar 7. Jarak Destinasi Pengunjung

Lama waktu kunjungan di Wisata Alam Gunung Pinang dibagi menjadi empat kategori yaitu, <1 jam, $1-3 \mathrm{jam}, 3-6 \mathrm{jam}$, dan $>6 \mathrm{jam}$. Lama waktu kunjungan $1-3$ jam mendapatkan prosentase tertinggi (Gambar 8).

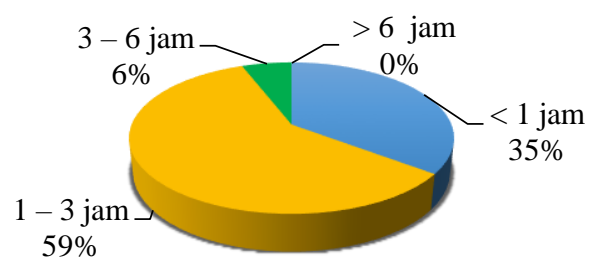

Gambar 8. Lama Waktu Kunjungan

Motivasi kunjungan di Wisata Alam Gunung Pinang didominasi oleh keinginan untuk rekreasi (88\%) sedangkan $12 \%$ kunjungan untuk mendaki gunung. Sedangkan 
bentuk kunjungan di Wisata Alam Gunung Pinang terbagi menjadi empat yaitu, sendiri, keluarga, teman dan rekan kerja (Gambar 9).

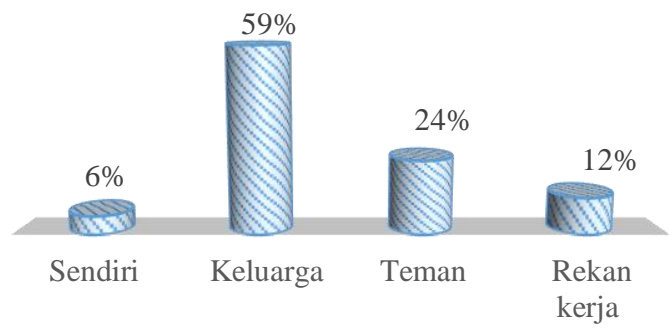

Gambar 9. Bentuk Kunjungan Pengunjung

Sumber informasi pengunjung berkaitan dengan Wisata Alam Gunung Pinang dibagi menjadi empat kategori yaitu, teman/keluarga, media cetak, media elektronik dan diri sendiri (Gambar 10).

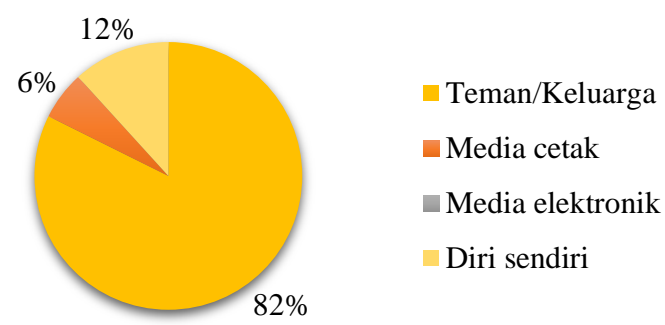

Gambar 10. Sumber Informasi Terkait Wisata Alam Gunung Pinang

\section{Karakteristik Masyarakat Sekitar Wisata Alam Gunung Pinang}

Masyarakat yang dimaksud dalam penelitian ini adalah pedagang, penjaga parkir dan penjaga wahana wisata. Mayoritas masyarakat di sekitar Kawasan wisata adalah laki-laki (60\%). Kelompok umur masyarakat 21-53 tahun terdapat $80 \%$, sisanya adalah kelompok umur $<21$ tahun (20\%). Sedangkan status pernikahan masyarakat sekitar wisata yaitu sudah menikah (60\%) dan belum menikah (40\%).

Pendidikan masyarakat terbagi menjadi lima kategori yaitu, SD, SLTP, SLTA, DIPLOMA dan SARJANA. Namun demikian hanya terdapat dua kelompok menurut tingkat Pendidikan, SLTA (70\%) dan SD (30\%).
Pekerjaan masyarakat dibedakan menjadi tiga kategori yaitu, penjaga wahana, pedagang dan penjaga parkir (Gambar 11).

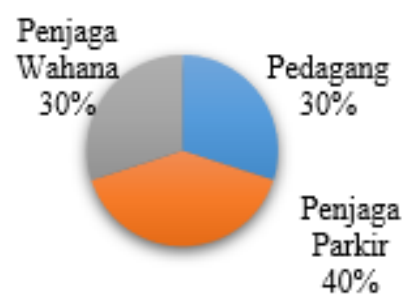

Gambar 11. Pekerjaan Masyarakat

\section{Persepsi Masyarakat Sekitar Wisata Alam Gunung Pinang}

Persepsi masyarakat merupakan pandangan masyarakat terhadap Kawasan Wisata Alam Gunung Pinang. Persepsi masyarakat mengenai potensi kawasan wisata dibedakan menjadi empat kategori (Gambar 12).

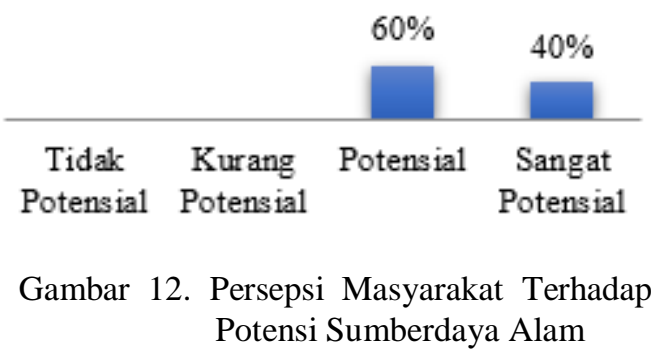

Penelitian ini juga mengukur persepsi masyarakat dalam mendukung kawasan wisata Gunung Pinang. Berdasarkan hasil penelitian, $60 \%$ masyarakat sekitar sangat mendukung pengembangan kawasan wisata (Gambar 13).

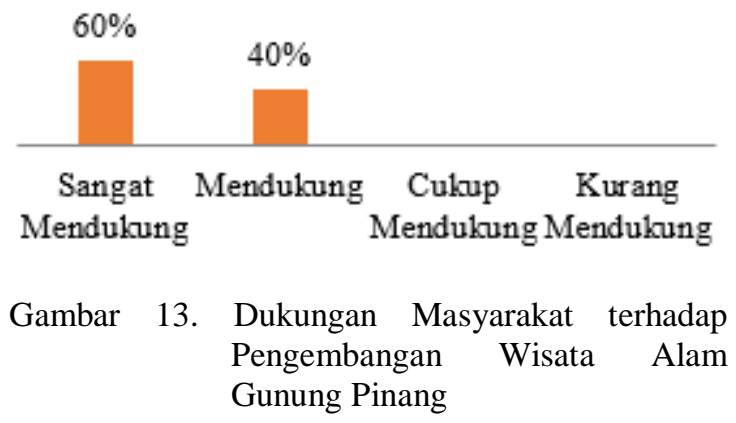




\section{Identifikasi Potensi ADO - ODTWA}

Berdasarkan pedoman ADO - ODTWA (Dirjen PHKA, 2003) penilaian potensi kawasan wisata terdiri dari tujuh kriteria, yaitu:

- Daya Tarik

Daya tarik merupakan hal yang penting agar suatu kawasan wisata layak untuk dikembangkan (Karsudi, 2010). Daya tarik merupakan komponen utama dalam menarik pengunjung untuk datang ke kawasan wisata. Penilaian daya tarik kawasan diberi angka 6, dengan skor total 1080.

- Aksesibilitas

Aksesibilitas berkaitan erat dengan kemudahan pengunjung dalam menjangkau sebuah kawasan wisata. Aksesibilitas menjadi salah satu komponen penting dalam tinggi atau rendahnya kunjungan wisata yang dilakukan oleh pengunjung (Hasibuan dan Cita (2020). Penilaian kriteria aksesibilitas diberi bobot angka 5, dengan skor total 575.

- Kondisi sekitar kawasan

Kondisi sekitar kawasan adalah salah satu penunjang dalam rangka pengembangan kawasan wisata. Kondisi sekitar kawasan yang diteliti adalah dalam radius $2 \mathrm{~km}$. Penilaian kriteria kondisi kawasan diberi bobot angka 5, dengan skor total 950 .

- Akomodasi

Akomodasi menjadi salah satu penunjang dalam kawasan wisata. Akomodasi berperan dalam mendukung kenyaman pengunjung. Penilaian akomodasi diberi bobot angka 3, dengan skor total 60 .

- Sarana dan Prasarana

Sarana dan prasarana menjadi salah satu penunjang untuk memberikan dan kenyamanan bagi para pengunjung dalam menikmati objek dan wahana wisata. Penilaian kriteria sarana dan prasarana diberi bobot angka 3, dengan skor total 150.

- Ketersediaan air bersih

Ketersediaan air bersih menjadi salah satu kunci penting dalam pengembangan kawasan wisata. Penilaian kriteria ketersediaan air bersih diberi bobot angka 6 , dengan skor total 660 .

- Keamanan

Keamanan yang terkontrol dengan baik akan membuat pengunjung meluangkan waktu lama saat melakukan kunjungan wisata. Pada kriteria ini diberikan bobot angka 5, dengan total skor 475 .

\section{Analisis Kelayakan ADO - ODTWA}

Kawasan Wisata Alam Gunung Pinang memiliki skor penilaian $81,63 \%$. Dengan demikian, secara umum dikategorikan layak untuk dikembangkan (Tabel 1).

Tabel 1. Analisis Kelayakan ADO - ODTWA Wisata Alam Gunung Pinang

\begin{tabular}{llrl}
\hline No. & \multicolumn{1}{c}{$\begin{array}{c}\text { Aspek } \\
\text { Penilaian }\end{array}$} & $\begin{array}{c}\text { Indeks } \\
(\%)\end{array}$ & \multicolumn{1}{c}{ Kategori } \\
\hline 1 & Daya Tarik & 85,71 & $\begin{array}{l}\text { Layak } \\
\text { dikembangkan }\end{array}$ \\
2 & Aksesibilitas & 83,33 & $\begin{array}{l}\text { Layak } \\
\text { dikembangkan }\end{array}$ \\
3 & $\begin{array}{l}\text { Kondisi sekitar } \\
\text { kawasan }\end{array}$ & 83,33 & $\begin{array}{l}\text { Layak } \\
\text { dikembangkan }\end{array}$ \\
4 & Akomodasi & 75,00 & $\begin{array}{l}\text { Layak } \\
\text { dikembangkan }\end{array}$ \\
5 & Sarana & 75,00 & $\begin{array}{l}\text { Layak } \\
\text { dikembangkan }\end{array}$ \\
6 & $\begin{array}{l}\text { krasarana } \\
\text { Ketersediaan }\end{array}$ & 85,71 & $\begin{array}{l}\text { Layak } \\
\text { dikembangkan } \\
7\end{array}$ \\
Keamanan & 83,33 & $\begin{array}{l}\text { Layak } \\
\text { dikembangkan }\end{array}$ \\
& $\begin{array}{l}\text { Tingkat } \\
\text { kelayakan }\end{array}$ & 81,63 & $\begin{array}{l}\text { Layak } \\
\text { dikembangkan }\end{array}$ \\
\hline
\end{tabular}

Sumber : Hasil Penelitian (2020)

\section{Analisis SWOT}

\section{a. Evaluasi Faktor Internal}

Faktor internal terdiri dari strength (kekuatan) dan weakness (kelemahan). 
Berdasarkan analisis lingkungan, faktor-faktor internal pengelolaan Wisata Alam Gunung Pinang diketahui sebagai berikut :

- Adanya daya tarik berupa keindahan flora dan fauna (S1)

- Adanya sarana dan prasarana (S2)

- Wisata Alam Gunung Pinang sangat strategi karena terletak di perbatasan Kabupaten Serang dan Kota Cilegon (S3)

- Adanya track sepeda gunung (S4)

- Kontribusi masyarakat dalam pengamanan wisata (S5)

- Pengelolaan dan pelayanan wisata belum maksimal (W1)

- Jarak pintu masuk menuju wahana wisata cukup jauh (W2)

- Pengelola kurang memaksimalkan potensi Kawasan (W3)

- Wahana wisata masih sedikit ragamnya (W4)

- Tidak ada penjualan cinderamata di sekitar kawasan wisata (W5)

Faktor-faktor internal yang sudah diketahui kemudian dievaluasi. Evaluasi bertujuan untuk mengetahui skor faktor internal (Tabel 1).

Tabel 1. Evaluasi Faktor Internal

\begin{tabular}{lccc}
\hline $\begin{array}{l}\text { Faktor Internal } \\
\text { Strength }\end{array}$ & Bobot & Rating & Skor \\
\hline S1 & 0,15 & 4 & 0,60 \\
\hline S2 & 0,13 & 3 & 0,39 \\
\hline S3 & 0,13 & 2 & 0,26 \\
\hline S4 & 0,13 & 4 & 0,52 \\
\hline S5 & 0,09 & 3 & 0,27 \\
\hline \multicolumn{2}{c}{ Total Nilai Strength } & & 2,04 \\
\hline Weakness & 0,09 & 4 & 0,36 \\
\hline W1 & 0,06 & 2 & 0,12 \\
\hline W2 & 0,07 & 3 & 0,21 \\
\hline W3 & 0,07 & 2 & 0,14 \\
\hline W4 & 0,06 & 2 & 0,12 \\
\hline W5 & & 0,95 \\
\hline \multicolumn{2}{c}{ Total Nilai Weakness } & 1,09 \\
\hline \multicolumn{2}{c}{ Nilai Faktor Internal }
\end{tabular}

Sumber : Hasil Penelitian (2020)

\section{b. Evaluasi Faktor Eksternal}

Faktor eksternal terdiri dari opportunity (peluang) dan treath (ancaman). Berdasarkan analisis lingkungan, faktor-faktor eksternal pengelolaan Wisata Alam Gunung Pinang diketahui sebagai berikut :

- Jumlah penduduk Banten tinggi sehingga kebutuhan terhadap wisata juga tinggi (O1)

- Rencana penambahan program dan wahana wisata (O2)

- Wisata Alam Gunung Pinang berdampak pada berkurangnya pengangguran $(\mathbf{O 3})$

- Pengunjung didominasi kaum milenial (O4)

- Lokasi wisata mudah dijangkau (O5)

- Pengembangan wisata sejenis sangat potensial dikembangkan sehingga berpotensi menjadi saingan (T1)

- Pengunjung kurang tertarik karena sedikitnya wahana (T2)

- Dampak berupa sampah dan kerusakan lingkungan (T3)

- Adanya tempat wisata di sekitar Wisata Alam Gunung Pinang (T4)

- Pengunjung memberi dampak negatif (T5)

Faktor-faktor tersebut kemudian dievaluasi agar dapat diketahui skor total faktor ekternal (Tabel 2).

Tabel 2. Evaluasi Faktor Eksternal

\begin{tabular}{lccc}
\hline Faktor Internal & Bobot & Rating & Skor \\
\hline $\begin{array}{cccc}\text { Opportunity } \\
\text { O1 }\end{array}$ & 0,12 & 4 & 0,48 \\
\hline O2 & 0,14 & 4 & 0,56 \\
\hline O3 & 0,10 & 3 & 0,30 \\
\hline O4 & 0,10 & 2 & 0,20 \\
\hline O5 & 0,08 & 3 & 0,24 \\
\hline Total Nilai Opportunity & & 1,78 \\
\hline Treath & & & \\
\hline T1 & 0,08 & 3 & 0,24 \\
\hline T2 & 0,09 & 2 & 0,18 \\
\hline T3 & 0,07 & 3 & 0,21 \\
\hline T4 & 0,12 & 3 & 0,36 \\
\hline T5 & 0,08 & 2 & 0,16 \\
\hline Total Nilai Treath & & 1,14 \\
\hline Nilai Faktor Eksternal & & 0,64 \\
\hline Sum : Hasil Penelitan
\end{tabular}

Sumber : Hasil Penelitian (2020)

\section{c. Penyusunan Strategi}

SWOT digunakan dalam menyusun strategi pengembangan ekowisata di Wisata Alam Gunung Pinang. Penyusunan strategi 
didasarkan pada faktor-faktor internal dan eksternal yang sudah didapatkan sebelumnya. Strategi yang disusun merupakan perpaduan dari faktor-faktor tersebut. Dengan demikian, akan didapatkan empat skenario penyusunan strategi :

\section{1) Strategi Strenghts-Oportunities (S-O)}

- Menjaga kelestarian daya tarik dan keindahan di Wisata Alam Gunung Pinang sehingga menjadi kepuasan bagi pengunjung

- Menambah sarana dan prasarana agar pengunjung dapat menikmati panorama alam dan akses informasi yang mudah

- Membuat paket perjalanan ekowisata di Wisata Alam Gunung Pinang bekerjasama dengan pihak tour travel.

- Melibatkan masyarakat dalam pembuatan program ekowisata.

- Meningkatkan promosi untuk menarik minat wisatawan lokal dan regional.

2) Strategi Strenghts-Threats (S-T)

- Menata Wisata Alam Gunung Pinang agar daya tariknya meningkat

- Berkoordinasi dengan Pemerintah setempat melalui kerjasama dalam pembangunan infrastruktur dan sarana prasarana.

- Membuat papan peringatan dan informasi terkait dampak rusaknya alam akibat kerusakan lingkungan sekitar.

- Melakukan pengembangan wisata baik penambahan sarana dan prasarana untuk meningkatkan nilai mutu kawasan wisata.

- Melakukan pembinaan terkat pentingnya menjaga budaya yang ada agar tidak terkontaminasi budaya luar.

\section{3) Strategi Weaknesses-Opportunities (W-O)}

- Rekrutmen pekerja sesuai kebutuhan dan memberikan pelatihan serta pembinaan bagi pegawai di lapangan
- Mengadakan kendaraan wisata untuk pengunjung sebagai daya tarik untuk menarik minat berwisata.

- Menambah wahana wisata yang beragam jenisnya untuk menarik minat pengunjung

- Mendirikan kios dagang cinderamata sebagai ciri khas Wisata Alam Gunung Pinang.

- Memaksimalkan segala potensi yang ada dan penambahan sarana untuk meningkatkan kepuasan pengunjung.

4) Strategi Weaknesses-Threats (W-T)

- Melakukan pendidikan dan pelatihan secara profesional dan bersertifikat

- Mengajak pemerintah dan masyarakat bersama sama melakukan promosi untuk pengembangan di Wisata Alam Gunung Pinang

- Melakukan pengembangan dan pemeliharaan sarana prasarana penunjang wisata

- Membuat program ekowisata alam dan sejarah sebagai wisata alternatif

- Melakukan pengembangan pedoman pembangunan sarana wisata yang menonjolkan keunikan Kabupaten Serang seperti masyarakat khas dan kerajinan souvenir.

\section{d. Penentuan Posisi Kuadran Strategi}

Berdasarkan hasil analisis yang sudah dilakukan maka dapat diketahui bahwa nilai $\mathrm{P}$ adalah 0,64 dan nilai $Q$ adalah 1,09. Dengan demikian, dapat ditentukan kawasan Wisata Alam Gunung Pinang berada pada posisi kuadran I. Kondisi ini menjelaskan bahwa Wisata Alam Gunung Pinang pada posisi Strength-Oppurtunity (SO), yaitu memiliki kekuatan untuk mengambil peluang yang ada.

\section{Rencana Pengembangan Ekowisata di Wisata Alam Gunung Pinang}

Berdasarkan analisis semua faktor yang telah dilakukan maka diperlukan rencana pengembangan ekowista di Gunung Pinang. 
Bentuk rencana tersebut berupa penambahan wahana wisata seperti, pengenalan satwa, pengenalan pohon dan pemberian bibit dan pengenalan produk perum perhutani.

Selain itu, pengembangan dilakukan dengan cara pembuatan program ekowisata. Rancangan program ekowisata dibuat dalam tiga bentuk :

- Program ekowisata harian SELASA (Sehari Jelajah Alam dan Berwisata)

- Program ekowisata harian SENJATA (Sehari Belajar dan Berwisata)

- Program ekowisata minat khusus sepeda

\section{SIMPULAN DAN SARAN}

Penelitian ini bertujuan untuk menilai obyek dan daya tarik wisata alam yang ada di kawasan Wisata Alam Gunung Pinang. Selain itu, untuk menganalisis permasalahan dan strategi pengembangan wisata alamnya

\section{A. Simpulan}

1. Kawasan Wisata Alam Gunung Pinang layak untuk dikembangkan

2. Strategi pengembangan ekowisata di Wisata Gunung Pinang dilakukan dengan cara menambah wahana wisata dan membuat program ekowisata

\section{B. Saran}

Beberapa hal penting yang dapat dilakukan untuk pengembangan pengelolaan Wisata Alam Gunung Pinang adalah :

1. Perlunya membangun komitmen dan kerjasama antara masyarakat, pemerintah dan kementerian terkait serta pihak swasta mengenai pembangunan Wisata Alam Gunung Pinang.

2. Pengadaan pelatihan bagi pihak pengelola dalam meningkatkan SDM dan penerapan peraturan mengenai pengelolaan.

3. Promosi kawasan wisata melalui berbagai media

\section{DAFTAR PUSTAKA}

Ali, Hasan. 2015. Tourism Marketing. Center for Academic Publishing Service. Yogyakarta.

Bahiyah C, Wahyu Hidayat R, Sudarti. 2018. Strategi Pengembangan Potensi Pariwisata Di Pantai Duta Kabupaten Probolinggo. Jurnal Ilmu Ekonomi Vol 2 Jilid 1/Tahun 2018 Hal. 95 - 103.

[Dirjen PHKA] Direktorat Jenderal Perlindungan Hutan dan Konservasi Alam. 2003. Penilaian ODTWA (Objek Daya Tarik Wisata Alam).

Hasibuan RS dan Ripki Taopik. 2019. Perencanaan Ekowisata Di Areal PT ANTAM Tbk, Bogor, Jawa Barat. TALENTA Publisher Universitas Sumatera Utara, tahun 2019 p-ISSN: 2654-7015, e-ISSN: 2654-7023, DOI: 10.32734/anr.v2i1.571

Hasibuan RS, Cita KD (2020). Penilaian Kelayakan Ekowisata Karst Cibadak Di Kecamatan Ciampea Kabupaten Bogor.

Karsudi. 2010. Strategi pengembangan ekowisata di Kabupaten Kepulauan Yapen Provinsi Papua. JMHT. 16(3):148-154.

Pitana, I Gede dan Gayatri, Putu G. 2005.Sosiologi Pariwisata.Yogyakarta: Penerbit Andi

Rangkuti, Freddy. 2014. Analisis SWOT: Teknik Membedah Kasus Bisnis. Jakarta. PT Gramedia Pustaka Utama

Sugiyono. 2009. Metode Penelitian Kuantitatif, Kualitatif dan R \& D. Bandung : Alfabeta.

Suryani E, Lalu Muhammad Furkan, Diswandi. 2020. Strategi Pengembangan Wisata Alam Hutan Irup Desa Saribaye, Kecamatan Lingsar, Lombok Barat. Jurnal PEPADU e-ISSN: 2715-9574 Online

http://jurnal.lppm.unram.ac.id/index.php/jurnalp epadu Vol. 1 No. 1, Januari 2020.

Zen AR, Sadjati E, Ikhwan M. 2018. Pemetaan potensi ekowisata di Desa Tanjung Belit dan Desa Lubuk Bigau Kecamatan Kampar Kiri Hulu Kabupaten Kampar Provinsi Riau. Wahana Forestra: Journal Kehutanan. 13(1):77-89. 